\title{
eVO|REG
}

\section{Are innovation systems complex systems?}

Emmanuel Muller ${ }^{1,2 *}$, Jean-Alain Héraud $^{2}$, Andrea Zenker ${ }^{1}$

1: Fraunhofer Institute for Systems and Innovation Research ISI, Karlsruhe (Germany)

2: Bureau d'Economie Théorique et Appliquée (BETA), Université de Strasbourg (France)

*Corresponding author: emmanuel.muller@isi.fraunhofer.de

evoREG Research Note \#33

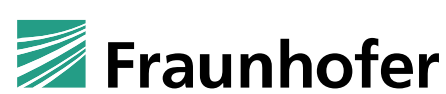

ISI

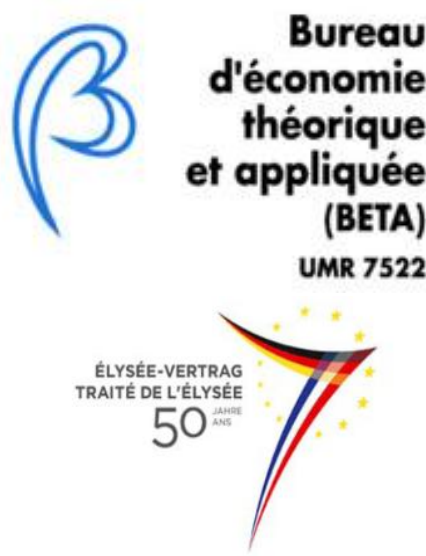

UNIVERSITÉ DE STRASBOURG

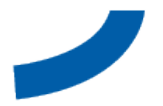




\section{Introduction}

Basically, complex systems are defined as a large number of autonomous entities in interaction, that create several levels of collective organization leading to emergent (and immergent) behavior. In short, complex systems are characterized by the observation that the whole is more than the sum of the parts (Aristotle). The aim of this paper is to address the issue of innovation systems in order to determine by how much they constitute complex systems.

Innovation systems are generally used by economists interested in depicting innovation processes, technological changes as well as the emergence of new fields in terms of knowledge, services or business models as an ensemble of resources committed to interrelated activities. Interestingly, only little importance has been given until now by evolutionary economics to the "complex-systemic" nature of innovation systems. Too often, such systems are just depicted as networks of actors.

So far, the main assumption was that an innovation system (e.g. a country, a region, specific sectors or technologies or a private firm) constitutes - taken as a whole - more than just the sum of its elements and that some feedback loops may be at stake related to processes and interrelations between actors. It is however important to go further in this analysis in considering the key features of innovation processes and thus identifying the reasons explaining why innovation systems may indeed be complex systems. The coordination between the different types of actors involved in the system as well as the existence of mechanisms ensuring a form of governance are at the core of the issue addressed. More precisely, the paper is an attempt to identify possible/thinkable systemic characteristics and properties.

The structure of the paper is the following. The first section deals with the concept of innovation as seen by evolutionary economists. The second and third sections consider different hypotheses in particular related to the issues of behavioral patterns and to nonlinear and non-predictable choices. The fourth section attempts to identify some emerging properties of innovation systems seen as complex systems whereas the fifth proposes some reflections about policy implications.

\section{What are innovation systems according to evolutionary economics?}

The "father" of the analysis of innovation in economics is without contest Joseph Schumpeter (1883-1950) who put forward the concept of "creative destruction". According to Schumpeter (1950) this process rules the historical evolution of capitalism. In 
this respect, five main types of innovation (Schumpeter 1935) can be distinguished: (i) new consumptions objects; (ii) new production and transport methods; (iii) new markets; (iv) new sources of production materials; and (v) new market positions (e.g. monopolistic situation).

Following seminal works by Schumpeter the field of evolutionary economics progressively emerged in the 50s' and 60s'. As a consequence, the concept of innovation systems was developed by authors such as Freeman (1995), Lundvall (1992), etc. At first this concerned mainly the so-called National Systems of Innovation (NSI). This in turn inspired reflections dealing with the sub-national level, i.e. the Regional Systems of Innovation (RSI). This last concept was made popular by authors such as Cooke (1998). Therefore, an innovation system can be considered as a complex system in the sense that it is composed of many subsystems that are different in nature while strongly articulated. Evolutionary economics consider innovation systems mainly under the aspect of creation/selection mechanisms and not so much in the framework of real systemic approach. The simplifying representation of neoclassical economics - the market providing all necessary information - is just replaced by another global mechanism, the selection process.

All in all, the main features of innovation systems in the field of innovation economics can be summarized as follows: (i) central role of learning; (ii) importance of historical processes; (iii) influence of institutions (public actors, legal framework, norms, etc; (iv) existence of feedback loops between non-fully rational actors; and (v) numerous and diverse interrelations between scientific, technological and organizational innovations.

A very interesting outcome is that those concepts have a real impact on the conception and application of public policies, especially in European Countries (at national and regional levels) as well as on the level of the European Commission (this point will be developed more extensively in section V). Nevertheless, and despite the wording usually adopted to name such systems, it clearly appears that the systemic nature of innovation systems is not really explored in the corpus of evolutionary economics. The following three sections will try to tackle this issue in presenting arguments in favor of the idea of innovation systems being complex systems.

\section{Innovation systems may be complex systems since they are based on complex behavioral patterns}

The crucial issue to be addressed is the following. If innovation systems are complex systems, what are the mechanisms that explain the mobilization and alignment of resources in an innovative direction? According to the literature, innovation systems are 
based on complementary mechanisms. The most important of such mechanisms are: (i) interactions; (ii) trial and error procedures; and (iii) selection.

Concerning at first interactions, no firm seems to be able to innovate without interactions with the "outside world". The forms and the actors involved in such interactions may be extremely heterogeneous but the existence of "autarkic innovations" seems to be extremely rare if not impossible. At the same time, an underlying process of "trial and error" can be found in every "innovation story". In other words, a "first shot" success may constitute a very unlikely exception. Moreover, it is helpful to keep in mind that many innovation projects fail. This leads finally to selection phenomena, which concern ideas, production and delivery processes, technologies, marketing approaches, types of interactions and collaboration and even actors (unsuccessful firms). One should be aware that the average life expectancy of companies is far lower than for instance the average human life expectancy.

One may easily recognize the evolutionary character of innovation systems. As a consequence, such systems can be seen as the results of complex behaviors of heterogeneous and numerous actors. Moreover, within such systems, different and variable ensembles of resources are committed to interrelated innovation activities (Stamboulis 2008). In other words, innovation systems may be complex systems since some behavioral mechanisms (and not "the market" as in the neo-classical economic approach) govern the alignment of resources, activities and efforts in innovative directions. These alignments consist in arrangements between actors and result from their - to a certain extent implicit and/or opposite - strategic decisions. This may be seen as a process of stretch and leverage taking place within an environment characterized by co-operation, connectivity and selection.

\section{Innovation systems may be complex systems since they result from non-linear and non-predictable choices}

Considering the heterogeneity of actors of any innovation system (e.g. firms, academic institutions, public actors, intermediaries, individuals, etc.), the issue can be addressed of what is "behind" their behaviors, choices and decisions and if those behaviors can be seen as corresponding to elements of complex systems.

At least two aspects play a crucial role in this context: First of all, the underlying assumptions of (neo-)classical economics such as perfect competition, full availability of information, atomistic markets, unbounded rationality, etc. are scrutinized and replaced by characteristics like humans' opportunistic behaviors, uncertain context conditions such as complex and unstable production environments, evolving structures, learning 
processes and so forth (see for instance Simon 1957). Scholars in evolutionary economics assume that complex economic processes - characterized by variety, technology development, firm evolution, etc. - are embedded in and interrelated with dynamic and uncertain contexts. Both parts - in our case innovating actors and their environment are influencing each other: Innovators' activities can (at least partly) be considered as response to their environment, but the overall environment is in turn also influenced through the activities of embedded innovation actors.

The second aspect to be considered refers to individual (innovation-related) actors and their 'views of the world'. It cannot be assumed that the totality of 'elements' in a system (here: innovation actors) behave in the same way, thus acting as a kind of 'uniform crowd', but that every individual has rather built up his/her individual model of the surrounding world. In short: human beings perceive the world in a specific way and create individual mental models of their surrounding which, in turn, strongly guide their behavior (e.g. Johnson-Laird 1983). Mental models are constructed on the base of memories, experiences, etc. which help to classify and interpret newly perceived information of the external world. Since context conditions including values, rules and habits are largely homogenous within innovation systems (at least in comparison with other systems), it can be assumed that members of the same system have converging views of the world (again compared with members of other systems, cf. for instance Stamboulis 2008).

\section{If innovation systems are complex systems what can be deduced from that?}

Summarizing the three previous sections, it can be stated that the complexity of innovation systems arises from interaction between actors, existence of feed-back loops and non-linearity of processes. Socioeconomic systems like innovation systems are also extremely difficult to describe because individuals have mental representations of the whole system and play strategic roles on the basis of those representations.

The strategic orientation of an innovation system results from more than just the sum or the aggregation of individual choices. Game theory applied to economics shows the extreme variety and instability of possible outcomes of strategic models. Nevertheless, even if behaviors cannot be predicted at individual level some patterns may exist and moreover the hypothesis can be formulated that some systemic properties may emerge. This is typically the case in physics, where independent particles in interaction may constitute a fluid, that will implement whorls and eddies under turbulent conditions even though Navier-Stokes equations cannot be found anywhere in the description of the particles. Then, in biology, a number of cells working together will implement an 
organ with properties going beyond those of each cell (the brains is more than a collection of neurons). Hundreds of ants in interaction will show intelligent behavior (finding the shortest path between their nest and a food source) that is beyond the reach of a single ant. On a higher level, is it possible to make the same observations with social networks (such as the Internet or even the stock exchange market)? Or are they complex systems of another type?

Then, observing only a part of a system may not allow drawing conclusions on some other parts. Local robustness is no indication on the robustness of the whole, due to retroactive loops, border effects and reflexive interactions.

However, collecting and observing data may allow creating a first model of a complex system that can be refined by subsequent simulations (and comparing the simulations to the observed data). The refined model can then be used to predict what can happen (in probability) in order to prevent catastrophes (in the sense of Thom 1989). Having a complex systems model for innovation systems will allow better understanding and predicting what conditions are needed for innovations to emerge.

\section{$5 \quad$ Implications for policy making}

Over the last decades, considerable efforts were made by public authorities in order to support economic development at different levels (national, but also regional, European...) with the clear goal of ensuring economic growth as base for employment, income and welfare. Innovation is understood as one means to contribute to economic development and thus wealth creation. On the micro level of business firms, innovation is a means to maintain or broaden market shares and thus to generate benefits.

Various policies address economic development, both via influencing the business environment and/or via supporting specific economic actors or actor groups. Fostering innovation follows this logic and - often based on the analysis of existing innovation systems - introduces interventions in order to create innovation-friendly framework conditions plus promotional measures for (potentially) innovating actors. With the broadening of knowledge and comprehension of innovation processes, policies also broadened and to an increasing extent included additional actors (e.g. from high-tech manufacturing firms to the inclusion of non-tech firms), their interrelations (e.g. collaborative innovation activities) and also switched to integrative policy approaches instead of unconnected approaches of individual policy fields. Equally, learning, exchange and gathering of experience received an increasing role (e.g. demonstrator cases, 'good examples, etc.). 
Several evolutionary aspects of innovation systems should be further considered from a perspective of complex systems:

- the existence of technological trajectories (for instance in the fields of the automotive or aerospace industries);

- the apparition of hybrid actors and/or mutational effects or even paradigm leaps through the emergence of permissive technologies (such as electricity or ICT);

- the impacts of learning effects and the resulting acceleration of knowledge flows which may be comparable to a certain extent to forms of swarm intelligence.

In consequence, and from a more general point of view, the following assumptions can be formulated in terms of implications for policy making if innovation systems are considered as complex systems. First, innovation-supporting policies should focus on issues related to actors' coordination rather than on optimization and efficiency. Second, only holistic innovation policies may be successful in the long-term and policy instruments must aim at providing good contextual conditions, rather than trying to manipulate individual behaviors. Third, and due to the non-linearity of the considered phenomena, if policies lead to mainly unpredictable events, the incentives mobilized by those policies should target marginal systemic effects rather than huge changes. If innovation systems are complex systems, then such approaches may support a reinvention of the role and legitimacy of public interventions dealing with innovation and economic development.

\section{Conclusion}

A better understanding of how far innovation systems can be considered as real complex systems would open new possibilities. In particular, some strong implications for public innovation-led strategies may result from sharper complex dynamics analytical abilities.

Nevertheless, the ideas developed in the previous sections are subject to limitations of different nature. First, only a few aspects of the broad spectrum of the concepts developed by academics about innovation systems are taken so far into account. Second, no quantitative data allowing the test of hypothesis are used in this paper. Last but not least, until now no attempt to propose some modeling of innovation systems as complex systems is proposed. Those limitations constitute avenues for future research. 


\section{References}

Cooke, P. (1998): Origins of the concept. In: Braczyk, H.-J.; Cooke, P.; Heidenreich, M. (Eds.): Regional Innovation Systems - The Role of Governance in a Globalized World. London: UCL Press, 2-25.

Freeman, C. (1995): The 'National System of Innovation' in historical perspective, Cambridge Journal of Economics, 19, 5-24.

Johnson-Laird, P.N. (1983): Mental Models. Towards a Cognitive Science of Language, Inference and Consciousness. Cambridge: Cambridge University Press.

Lundvall, B.-Å. (Ed.) (1992): National Systems of Innovation. Towards a Theory of Innovation and Interactive Learning. London: Pinter Publishers.

Schumpeter, J.A. (1950): Capitalism, Socialism and Democracy. New York: Harper and Brothers.

Schumpeter, J.A. (1935): The analysis of economic change, Review of Economic Statistics, 17, 2-10.

Simon, H. (1957): Models of Man. New York: Wiley.

Stamboulis, Y. (2008): Exploring the System Dynamics of Innovation Systems. Athens, Greece: System Dynamics Society. Online:

http://www.systemdynamics.org/conferences/2008/proceed/papers/STAMB454.

Thom, R. (1989): Structural Stability and Morphogenesis: An Outline of a General Theory of Models. Reading, MA: Addison-Wesley. 